\title{
THE TRADITIONAL ARAB ISLAMIC CITY: THE STRUCTURE OF NEIGHBORHOOD QUARTERS
}

\author{
Loai DABBOUR (iD ${ }^{*}$ \\ Department of Architecture, Faculty of Architecture and Design, Al-Zaytoonah University of Jordan, Amman, \\ Jordan
}

Received 30 June 2020; accepted 04 June 2021

\begin{abstract}
This paper is concerned with the structure of quarters in traditional Arab Islamic cities. Previous studies have stressed the idea of an urban structure that corresponds to social groupings, in that it is seen as a collection of neighborhood quarters. This spatial model has often provided the rationale for the design of new housing layouts. The purpose of this study is to examine this issue and to argue that the structure of these cities presents a global whole. To achieve this purpose a general and a specific question are addressed. The general question is about the physically sub-areas within the city, and the specific question is about the issue of social groupings and the kind of relation that space has to society. The proposition thus invokes the idea of a physical structure which appears to correspond to a social pattern. The city of Damascus is used as a model of analysis in which the urban structure is described and characterised. The argument is advanced that the traditional Arab Islamic city has a sub-area structure which is historically generated, but whose morphological combination is fine-tuned and adjusted so that the whole comes to dominate and unify the parts.
\end{abstract}

Keywords: Islamic city, neighborhood quarters, traditional urban structure, quarter's structure, social groupings.

\section{Introduction}

The structure of neighborhood quarters in traditional Arab Islamic city invokes the idea of a physical layout which appears to correspond to a social grouping. By that, local quarters (Hara), each defined by an urban block become physical mediators between the primary elements of the city, the set of buildings or closed cells, and the overall physical form of the city. This gives a practical directive to resolve what seems to be a difficult question which is a constant source of debate amongst researches: how the sub-areas of the city - quarters (Hara), neighborhoods (Hai), localities and the like - are formed into a larger whole?

The point about the parts/whole, local/global issue in traditional urban form is that it is a general problem about the structuring and functioning of cities. The idea of the quarters structure is proposed by many researchers as the answer to this question in traditional and unplanned cities. The complex of ideas seems so natural that it is seldom brought into question. Where it is usually examined from a social perspective to show that physical contiguity is no guarantee of real or perceived community identity. This argument does not really challenge the basic principle that if space matters to society it is through some hierarchy of socio-physical correspondences.

If such a theoretical entity as a "neighborhood quarters structure" exists within traditional Arab Islamic cities, it should be apparent in the physical fabric alone without reference to society. Clearly, order-based analyses are not sufficient to settle the issue, since these rely on those very characteristics which, it is argued, are not fully developed in "disordered", "organic" urban forms like the traditional Arab Islamic city. The matter can only be resolved by tackling the physical description of urban forms at the level of structure. This paper therefore sets out to investigate the physical fabric of the traditional Arab Islamic city to see if beneath the apparent "disorder" any such entity as a "neighborhood quarters structure" can be shown to exist, and to arrive at a clear characterization of its structure through a systematic description of the local aspects of its structural elements and how it relates to the global structure of the city.

A study of this nature has both a specific and a generic interest. The general significance lies in the fact that the traditional Arab Islamic city is frequently cited

*Corresponding author. E-mail: loai_dabbour@hotmail.com 
as an example of the general proposition about the hierarchy correspondence relation between space and society in traditional or "organic" cities. It is widely believed that these cities are a collection of quarters, in which it is taken for granted that social identity is supported by a degree of physical self-containment (Perry, 1939; Le Tourneau, 1961; Von Grunebaum, 1961; Al-Hathloul, 1981; Rapoport, 1982; Brown, 1986; Bianca, 2000; Can \& Heath, 2016). The concept of self-contained city quarters and neighborhoods was developed by French scholars working in and on North Africa, such as the Marçais and Massingnon. They see the quarters as the fundamental building block of the Muslim city. These quarters are distinguished by the ethno-religious origins of its inhabitants and by their occupations, separated and closed, with gates and walls (Goddard, 1999; Eickelmann, 1974). Moreover, Weber's conception of Islamic society, which includes city structure, contributed to the emerging notion of the "mosaic nature' of the Islamic city. The idea is that the Islamic social structure is a mosaic or patchwork of religious groups and social organizations" (Goddard, 1999). The same concept is developed by Jean Sauvaget, in his study of Damascus and Aleppo. He proposes the dividing up of the city into an "aggregate of quarters" each of which over time became an almost self-sufficient and self-contained entity with its own markets and mosques. $\mathrm{He}$ concludes that the Islamic city was fundamentally a "mosaic of quarters" without any municipal institutions (Greenshields, 1980; Goddard, 1999). Lapidus refers to the same concept as "the basic units of society" in Islamic urbanism and urban social structure. For him quarters defined by certain shared ethnic, religious, economic, and regional identities were developed into quite self-sufficient and defined communities with their own social, political, and economic structures (Lapidus, 1969, 1970).

If this is the case, then this should be revealed directly by configurational analysis of the physical structure of the traditional city. However, these cities appear from its foundation to have been morphologically differentiated in its parts but integrated as a whole, although the precise way in which this was achieved seems to have varied with historical periods and phases of growth. This is clearly at odds with the hierarchical order-based concept of a correspondence between clear physical domains and bounded social groupings, since this implies an identity of local elements. To the extent that morphological differentiation in the sub-areas of the city exists, then some alternative formulation about quarter grouping to the hierarchy/correspondence formulation may emerge which is capable of a more general application to naturally evolved cities.

Eickelman in his research on "the making of a quarter in a Moroccan town" argues that a quarter can be defined as "the extension of social ties (qaraba) in a contiguous physical space". But since social relations are never static, quarters in both the physical and social sense are also never fixed; the quarter is a fluid entity that can expand, decline and at times even completely disappear. This reality along with the fact that the concept of (qaraba) applies not just to quarters, but also to other social ties, both urban and rural, proves that the quarter is not "a form of association distinct to urban life". His findings can correspond to more historical account (Eickelmann, 1974).

The specifics significance lies in the fact that these cities are known to have had a "devolved" institutional structure (quarters) and trade groupings were all locality- specific or at least regionalized within the city (Luz, 2014; Lapidus, 1970; Serjeant, 1980; Hakim, 1986; Akbar, 1988, 1992). This might be suggestive of a correspondence between space and society. Other aspects of social life which are widely thought to have been systematically spatialized, point in the opposite direction to a non-correspondence of society and space, the spatially proximate relationship of rich and poor being a case in point. The location of important non-residential buildings may have been such as to exploit systematically some aspect of morphology. However, a modest aim of this paper is to investigate the parts/whole question as initially posed in the neighborhood quarters studies on Islamic city proposition to explore the extent to which these known socio-cultural phenomena can be shown to have spatial correlates. If the relation is found not to be straightforward; that is, not a correspondence projection or reflection of social groups and institutions, then this may provide some clue to an alternative hypothesis about the social strategy which was adopted in relation to the "deformed" urban structure of the traditional Arab Islamic city.

\section{The spatial correlations of neighbourhood quarters}

In traditional Arab Islamic cities, the process of historic growth has, it is argued, naturally brought about sub-area identity within these cities. According to Azzam, Raymond Lapidus and Hakim, the formation of such localities was due to historical or socio-economic factors; such as the waves of immigrants that used at a certain point to form separate quarters mainly due to the fact that they could maintain their identity with the main community without causing too much conflict, like the Turkomans and Kurds in Aleppo and the Andalusians in Fez and Tunis (Azzam, 1993; Raymond, 1985; Lapidus, 1969; Hakim, 2007). This process should generate a type of city in which the overall physical form arises as an aggregation of isolated sub-areas, each of which has a well-defined character as well as an identifiable social aspect. If each sub-area arose spontaneously without overall coordination, the street system of each tends to be self-referential, at the expense of the overall network which tends to be relatively discontinuous and fragmented. Even if the precise boundaries of the quarters are not absolutely clear, they will tend to be separated by major streets and offset from one another, so that direct physical access from one part of the city to another is minimized. The physical structure of sub-areas guarantees that the quarters circumscribes a sphere of daily movement and social encounter. 
It is suggested that a clue to the identity of natural sub-areas might be given by the requirement for residents jointly to perform civic duties. Among the examples cited are that each quarter has its own section of the walls to defend political unity based on common rights and religious affiliation as reflected in mosque boundaries or pattern of work through occupational association, by means of which professions of the same sort tend to form well-defined quarters (Elisseff, 1980; Ferwati, 2010; Habib et al., 2013). The main destructive influence on the survival of these sub-areas is seen to be the necessity for through movement which by creating a more global connectivity within the city ruptures the self-contained structure of the quarters such that it is easier to find oneself in the city as a whole than to find oneself in the quarter.

In this, particular attention will be paid to the urban fabric and the local configuration of the quarters in the traditional Arab Islamic city as it is given by the structure of the urban fabric. What is significant for this is that writers like (Azzam, 1993; Lapidus, 1967, 1969; Hourani, 1970; Remali \& Porta, 2017) set out a clear physical specification detailing the conditions under which quarters might be said to exist. If this is the case in traditional Arab Islamic cities, it should be possible to identify within its configuration spatially discrete entities which have some social significance in terms of occupational grouping, political or administrative association or common interests.

\section{The local fabric of the traditional Arab Islamic city}

The reconstructed maps of traditional Arab Islamic cities (Damascus, Aleppo, Tunis and Fes) in Figure 1 give a broad statement about the public space description of the city which is necessary to establish the validity of the quarter's concept. Taking first the block structure, the first impression is one of disorder. Island blocks appear to vary greatly in size, shape and composition. Urban blocks are not laid out in a form which would result from the division of the block in conventional block plots, nor are they under single ownership. On the contrary, each may have several property holdings which may or may not be permeable to neighboring holdings on the different faces of the same block (Duri, 1980; Woodford, 1990; Hertani, 1991). Visually identifying the major discontinuities in the urban fabric given by what seems to be the most striking patterns in the structure of urban blocks in the traditional Arab Islamic city throws up precisely the same problem: sometimes the blocks are relatively easy to identify and sometimes it is difficult as to which are major and which are minor routes, and in how the small-scale blocks are aggregated into larger-scale blocks seems to be intrinsic to the nature of the traditional Arab Islamic city. This is in direct contrast to the prediction of physical clarity which results from neighborhood unit literature.
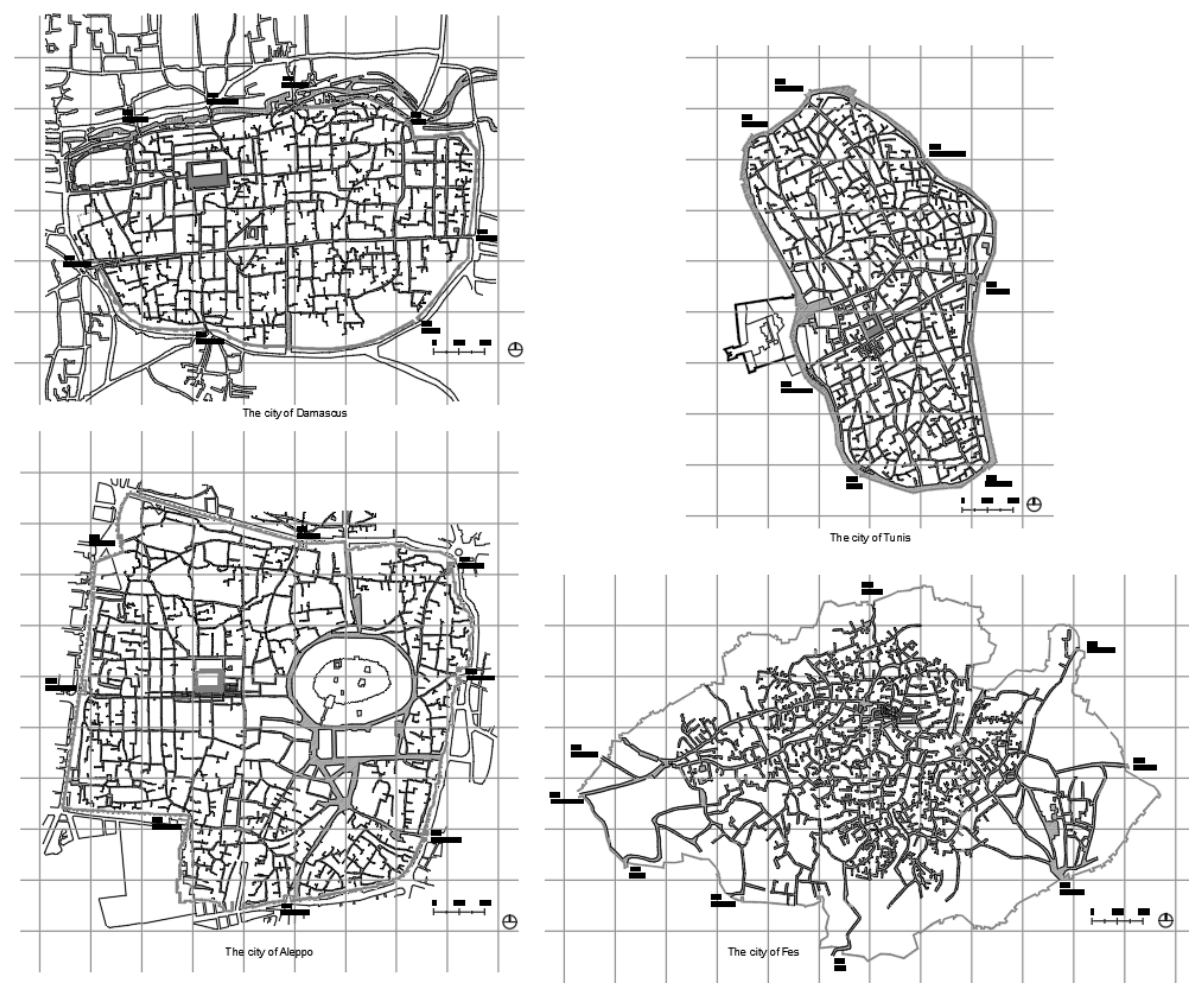

Figure 1. Traditional Arab Islamic city: Ground plan showing the spatial structure of the city (Damascus, Aleppo, Tunis and Fes). The city of Damascus (source: author; Pascul, 1983; Sack, 1989; Chamberlain, 1994; Raymond, 1984, 1997; Sauvaget, 1934; and planning and studies dept. Municipality of Damascus). The city of Tunis (source: author; Hakim, 1986; Woodford, 1990, Raymond, 1989; Azzam, 1993). The city of Aleppo (source: author; Gangler, 1993; Raymond, 1984; Marcus, 1989; Hertani, 1991; and planning and studies dept. Municipality of Aleppo). The city of Fes (source: author; Gaudio, 1982; Le Tourneau, 1961; Azzam, 1993) 
The basic pattern of development of a plot seems to have been that first a single house was erected parallel to the street. This was then followed by a row of houses turned on to the street, finally, these were augmented by a back to back development of closed court houses around the property boundary in the public space of the plot. Large private houses were the exception. Throughout the city these were embedded in the heart of the block with access by way of an alley (Cul-De-Sac) (Zoukak) leading to a front courtyard (Figure 2). Lager buildings ought to have been associated with principal streets and smaller buildings with minor streets. This would have paralleled the logic of neighborhood unit planning which also tends to group similar classes of dwelling and occupant together. However, within the traditional Arab Islamic city itself this principle is not followed consistently and most frontages contain a mix of property sizes (Figure 2).

A by- product of the structure of urban blocks within the city is that the houses of the wealthy are contiguous with everyday dwellings, and everyday dwellings with the houses of the poor. This degree of spatial contiguity is unacknowledged by the literature on neighborhood quarters, which prefers space to associate the homogenous elements within society and to separate the heterogeneous. The traditional Arab Islamic city is also characterized by a lack of large scale, public open space. There is no cartographic evidence in the traditional Arab Islamic city of any attempt to scale public spaces to correspond to local foci of neighborhood centers. The two striking large scale spaces; the great mosque and the madrash's (school) courtyards are a product of these only two monumental buildings of the city. They add significance to these buildings by emphasizing their symbolic role through geometry. Both are historically associated with public gathering places. The places were, however, used for outdoor preaching and functioned as gathering places for the entire citizens.
The street system and structure appears highly deformed and irregular, although some streets which had been designated as major thoroughfares were substantially widened and most minor lanes were made around $4.5 \mathrm{~m}$ wide, there had been little attempt in the building process to geometries the city in accordance with the existing Roman principles of town planning, as in the case of Damascus for example. The city seems not to be composed of locally similar elements but of dissimilar parts which are aggregated and bound together by the line of the walls, and limited within their confines by the dynamics and constraints which govern the global structure of the street layout. Moreover, since there seem to be pronounced physical differences in the street structure and in the shapes of the islands contained by it, this raises the question as to whether these observable differences bear any relation to the structure of city neighborhood quarters, whether these be purely a product of spatial configuration or bear the imprint of society and its institutions?

The question also arises as to the relationship between the parts and the whole. One possibility is that this coming together is merely fortuitous: that is, the parts are simply collected together in a spatially contiguous relationship whilst preserving local independence and discreteness. This would imply the dominance of the "quarter" of the city over the overall development of the configuration. This possibility would lend the belief to the view that the traditional Arab Islamic city is indeed a collection of distinctive and relatively self-contained urban quarters. At the other extreme, it is conceivable that the differentiated parts might nonetheless be subordinated and integrated within a more global urban structure. Under these circumstances, the concept of the neighborhood quarters structure would require a radical reformulation. As a result of this, a methodological procedure will be adopted of inspecting the city in quarters. All-important configurational features in which the city seems to differ in its parts will be examined to see if differences in the distributions of spatial and other properties emerge.

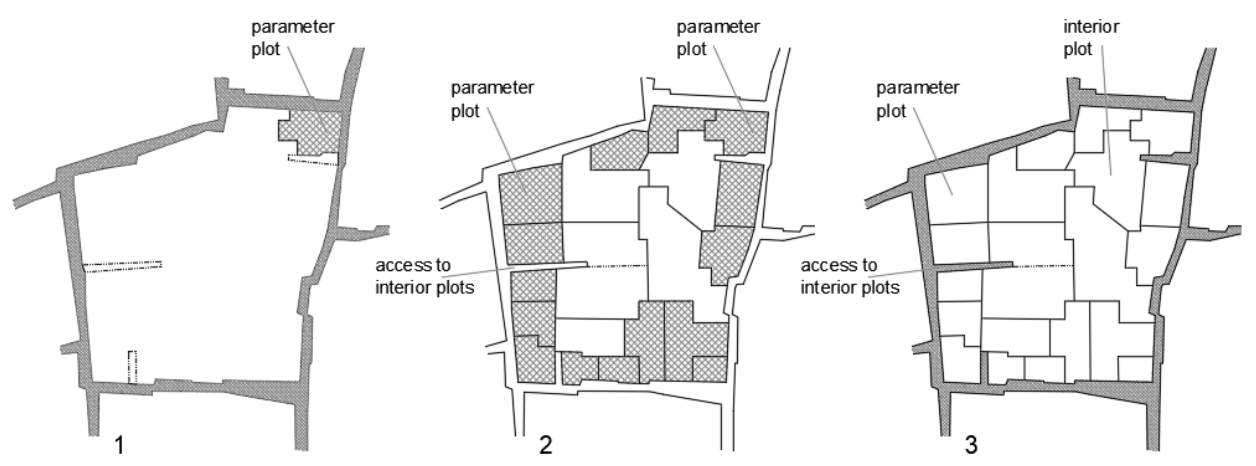

Figure 2. Property sizes in relation to the block structure/varies property sizes associated with the outer segments of the block boundaries. The pattern of development of a typical plot block: 1 - a single house is erected parallel to the streets; 2 - this is followed by row of houses turned to the streets leaving the heart of the plot as a public area; 3 - houses are erected in the plot public area forming Cul-De-Sac as an access system (source: author) 


\section{The spatial structure of the quarters}

Many researchers have noted the lack of harmony between quarter boundaries and physical features within the city (Azzam, 1993; Raymond, 1997; Bianca, 2000; Khoury, 1984). That this is so is immediate and striking. In Damascus for example, An-Naqqasat quarter and Amara Guwaniya quarter almost split in two, and in each case the segments are connected only by the width of a minor street which maintains spatial continuity. Maidan Al-Sham quarter within is physically split, being discontinuous with Medhat Basha street with a small part in the north and the major area in the south. At the wall, Bab Tuma quarter and $\mathrm{Al}$-Antus quarter within do not cross the physical boundary. Bustan Al-Qitt quarter prevents the quarters in the southern part of the city from reaching the wall at all (Figure 3). This already presents some puzzles for the neighborhood quarters structure concept for it is clear, particularly where quarters are crossed by streets that daily contact and social intercourse are severely impeded by the irregular shape of quarters.

The size of the quarters varies greatly. In the case of Damascus for example as shown in Table 1; the largest Harat Al-Yahud quarter (15 ha) and Bab Tuma quarter (13 ha) are nearly seven times the size of the smallest, Suq Al-Harir quarter (2 ha) (Suq/Market). Mean quarter size is (6 ha). All the larger quarters are close to the walls (Figure 3). The shape of quarters to area-perimeter ratios is difficult to standardize. Quarters within the city display articulation of two sorts; some, like in Damascus for example (Figure 3) Nabat and An-Naqqasat quarters are regular in overall shape, but have locally jagged boundaries. Others, like Sallaha and Harab quarters, have jagged boundaries locally but in addition take up a highly irregular overall shape. This overall irregularity is difficult to reconcile to the neighborhood quarters ideal, since it reduces the possibility for conceptualizing the quarter as a physical entity, particularly when it is experienced as a built reality rather than in plan.

This articulation of boundaries in the quarter structure has an important effect on the neighbor condition of quarters. Were the quarter structure of the city to have taken a perfectly rectangular form, then each block would have exactly four neighbors. The non-rectangular outline of quarters has a simple "socio-physical" effect of increasing the number of potential neighbors for the majority of cases. If adjacency over a short distance is counted as sharing a common boundary, but corner joining is disallowed, then the average number of adjacent neighbors of quarters within the city of Damascus is 4.5 . Those along the walls suffer by not being able to make joins on all four sides, but even these have an average of 3.9 neighbors. In the center of the city this rises to 4.8. The lowest value is that of Bain As-Surain quarter which is enfolded by one quarter, and the highest is Maidan Al-Sham quarter, which has 7 neighbors. That the articulation of the boundary enhances neighbor adjacency seems to run counter to the neighborhood quarter concept, which stresses the degree of selfcontainment and physical discreteness of neighborhoods to a degree which does not allow for physical interlock.

More important than area-perimeter ratio is the boundary condition of quarters, since this is one area where the neighborhood quarter concept might be expected to assume a clear physical form. It has been suggested by some historians that the quarters were originally determined by the lines of the principal roads (Lapidus, 1967; Hourani, 1970; Eickelmann, 1974; Serjent, 1980), so that the road marked the boundary between adjacent quarters. This would be in line with the expectations of the proponents of neighborhoods unit. A "weak" version of neighborhood quarter concept would anticipate that where this was not the case, the road network would still be such as to render access from one quarter of the city to another difficult.

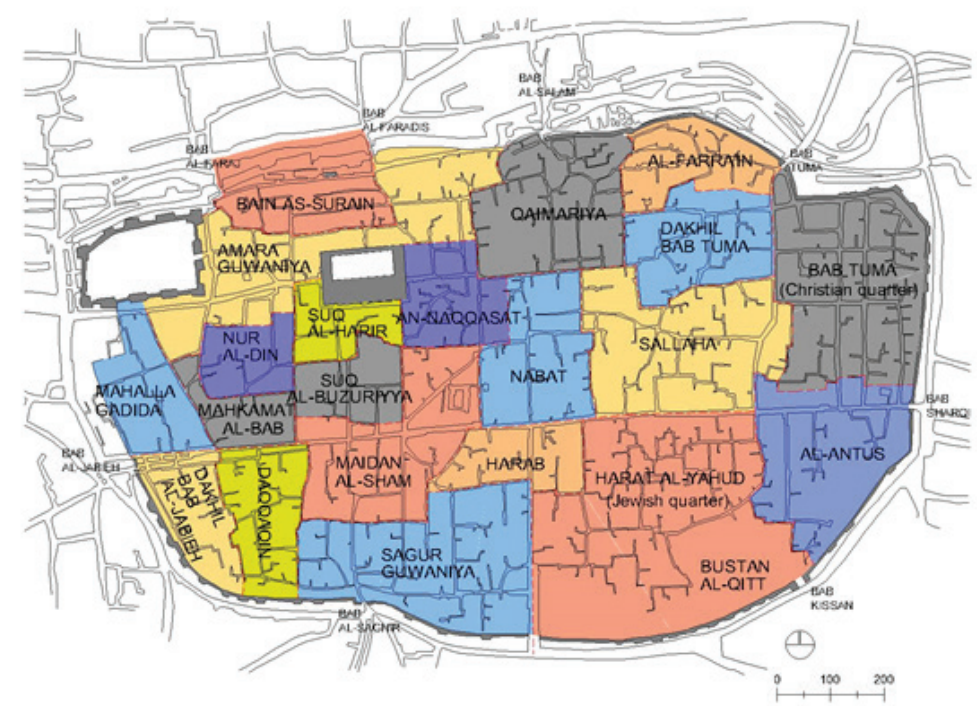

Figure 3. The structure of quarters in the city of Damascus (source: author; Khoury, 1984; Sack, 1989; Chamberlain, 1994; Raymond, 1984, 1997; Pascual, 1983; Sauvaget, 1934) 
Table 1. The area of the quarters in the city of Damascus (source: author)

\begin{tabular}{|c|c|c|}
\hline Quarter & Size $\mathrm{km}^{2}$ & Size hectares \\
\hline Mahalla Gadida & 0.06 & 6 \\
\hline Mahkamat Al-Bab & 0.02 & 2 \\
\hline Nur Al-Din & 0.05 & 5 \\
\hline Amara Guwaniya & 0.07 & 7 \\
\hline Bain Al-Surain & 0.07 & 7 \\
\hline Suq Al-Harir & 0.02 & 2 \\
\hline Suq Al-Buzuriyya & 0.03 & 3 \\
\hline An-Naqqasat & 0.03 & 3 \\
\hline Qaimariya & 0.08 & 8 \\
\hline Nabat & 0.06 & 6 \\
\hline Sallaha & 0.08 & 8 \\
\hline Dakhil Bab Tuma & 0.07 & 7 \\
\hline Al-Farrain & 0.02 & 2 \\
\hline Bab Tuma & 0.13 & 13 \\
\hline Dakhil Bab Al-Jabieh & 0.04 & 4 \\
\hline Daqqaqin & 0.05 & 5 \\
\hline Maidan Al-Sham & 0.07 & 7 \\
\hline Harab & 0.03 & 3 \\
\hline Sagur Guwaniya & 0.10 & 10 \\
\hline Harat Al-Yahud & 0.15 & 15 \\
\hline Al-Antus & 0.06 & 6 \\
\hline Average & 0.06 & 6 \\
\hline
\end{tabular}

Figure 3 shows that the view that quarters are separated by major through streets in the city of Damascus contains little of real substance. In the case of the city of Fez for example (Figure 4), the boundary between El-Oyoun and El-Tal'a quarters and with El-Oyoun and El-Gernis and Ras Jnan is not a principal through-route. In the west, Zkak Er-Romman and Ech-Chrabliyin are separated by a series of lanes, and the north-south boundary of Zkak Er-Romman quarter with Fondok El-Ihoudi and El-Blida also follows minor streets. The only boundary which is constructed along an important street is that between ElKettanin and Es-Sagha quarters but even here the street concerned is important for movement about the city rather than into and across it. Quarter El-Tal'a is separated by two major streets (Tal'a Kubra and Tal'a Sughra streets) and still considered as one unit the same can be noticed in Ech-Chrabliyin quarter.

The same can be noticed in the city of Aleppo (Figure 4), Suwayqat Hatem quarter and Al-Dabbagha Al-Atiqa quarter almost split in two, and the quarters are connected in a way which maintains spatial continuity. The same situation occurs between Al-Masabin quarter and Aqaba quarter in which there is no actual physical boundary to define the boundaries of the quarters. Dakhil Bab Qinnasrin quarter and Gallum Al-Sughraquarter are split by the width of a minor street which also maintains spatial continuity.

These discrepancies in the quarter's boundaries raise the question of how these boundaries were determined from the first place. To answer this question two approaches will be considered; first the issue of mental maps and mental images will be tackled to see how the inhabitants realize and perceive the boundaries of their quarters, second, the issue of quarter gates which was raised by many researches (Lapidus, 1969; Hourani, 1970; Eickelmann, 1974; Azzam, 1993; Raymond, 1997) as a physical boundaries determining the boundaries of the quarters will be superimposed on the quarter's boundary map to see their correspondence with these boundaries.

Mental maps and the concept of mental images were used by Lynch in studying how the urban space is conceived and understood by the residents of the city. It is about the perception of quarter boundaries by the inhabitants, it is to understand how residents set these boundaries and in relation to which physical barriers (Lynch, 1981). To investigate this, a simple exercise was carried out to draw these boundaries of Sugur Guwaniya quarter in Damascus, in which 65 residents in this quarter were
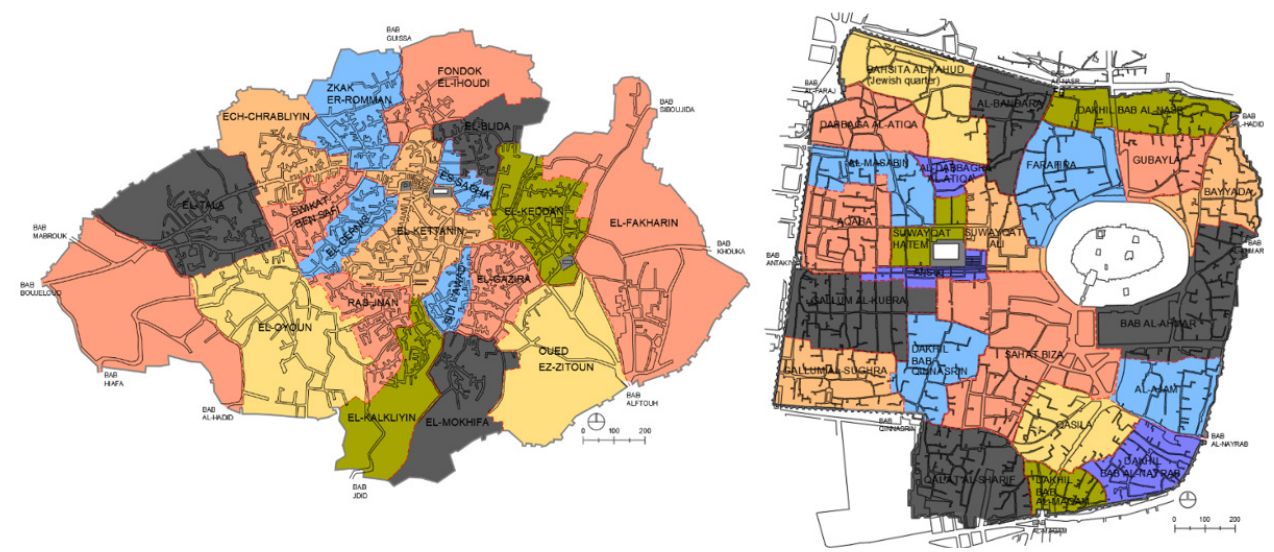

Figure 4. The structure of quarters in the city of Fez (source: author; Gaudio, 1982; Le Tourneau, 1961; Azzam, 1993). And the city of Aleppo (source: author; Gangler, 1993; Raymond, 1984; Marcus, 1989; Hertani, 1991; and planning and studies dept. Municipality of Aleppo) 
Table 2. Record of the interviewed residents of Sugur Guwaniya quarter in the city of Damascus (source: author)

\begin{tabular}{|c|c|c|c|c|c|c|}
\hline Age group & 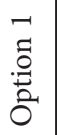 & 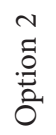 & $\begin{array}{l}\text { n } \\
\text { : } \\
\text { مै } \\
0\end{array}$ & $\begin{array}{l}+ \\
\text { +0 } \\
.0 \\
0 \\
0\end{array}$ & $\begin{array}{l}\text { n } \\
\text {.0 } \\
\text { مै } \\
0\end{array}$ & Total \\
\hline $18-34$ & 3 & 4 & 4 & 5 & 6 & $22(8 \mathrm{M}, 4 \mathrm{~F})$ \\
\hline $35-54$ & 3 & 4 & 4 & 6 & 7 & $24(15 \mathrm{M}, 9 \mathrm{~F})$ \\
\hline 55-or older & 2 & 3 & 4 & 4 & 6 & $19(12 \mathrm{M}, 7 \mathrm{~F})$ \\
\hline Total & 8 & 11 & 12 & 15 & 19 & $65(35 \mathrm{M}, 20 \mathrm{~F})$ \\
\hline
\end{tabular}

interviewed and asked to set the quarter's boundaries from their perception. The residents were selected from routes that cover a full range of the quarter's boundaries to cover the following criteria: age groups (18-34, 35-54, 55-or older), gender, and living experience (at least 5 years of continuously living in the quarter). Table 2 illustrates the distribution of the sample in accordance with the quarters options.

The results are gathered in (Figure 5). In conclusions we noticed that first, $86 \%$ of interviewed residents located the quarter boundary by referring to local streets as physical boundaries and $14 \%$ referred to the quarter boundaries by naming households. Both of these two groups referred to the local mosque as the center of the quarter. Second, residents of the same quarter have different mental images of the quarter boundary with no specific reason. This may explain that we have different records representing different boundaries of the quarters of traditional Arab Islamic city.

In Sugur Guwaniya quarter in Damascus the households on the quarter's parameters were interviewed to see why they were included or excluded from the quarter's area. In conclusions the local mosque came as the ma- jor factor in including or excluding households from the quarter's boundaries, $89 \%$ of the interviewed residents related themselves to the local mosque, $11 \%$ related themselves to social ties within the quarter boundaries. As an example of the survey, it is interesting to note that two of the residents of Sugur Guwaniya quarter (marked on Figure 5), used to consider themselves part of other quarters, house A used to consider himself part of Maidan Al-Sham quarter because he used to pray in the local mosque located in Maidan Al-Sham quarter; and house hold B used to consider himself part of Daqqaqin quarter again because he used to pray in the local mosque in this quarter. It is interesting that both now consider themselves as part of Sugur Guwaniya quarter because now it is there were they practice their prayers, and this change of mental boundaries is caused by their personal decision where to practice their prayers.

The second approach in understanding the discrepancies in quarter boundaries is through looking at these boundaries in relation to the quarter/street gates. For this purpose, the quarter/street gates of the city of Damascus are superimposed on the quarter's structure map, the result map in shown in Figures 6 and 7. We can notice that there is a weak relation between the boundaries of the quarters and the positions of the quarter/street gates. Looking first at the street gates which are divided into two types according to Sack; lockable and not lockable gates (Sack, 1989) (Figure 6). In Figure 7 the positions of all the lockable street gates are located to define a boundary of a Cul-De-Sac. This make sense, as it is located to define a private property owned by private party leading to a single or limited number of houses usually owned by one family or extended family. In other words, the owners of the Cul-De-Sac have the right to control the space use and movement within their local zone (Akbar, 1988, 1992).
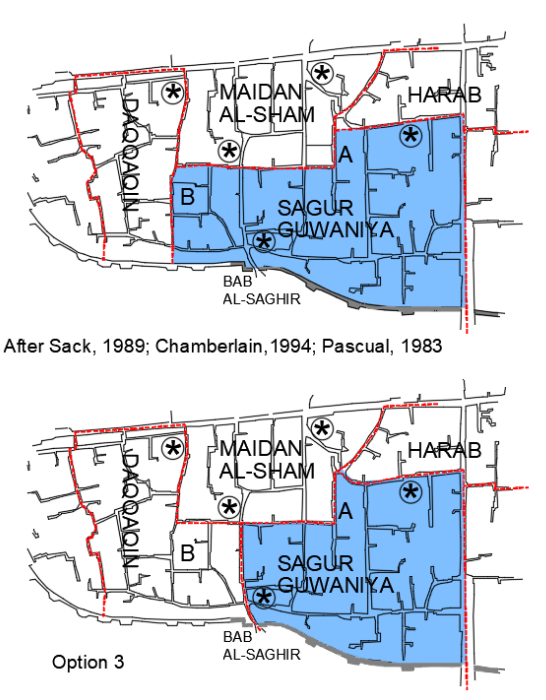
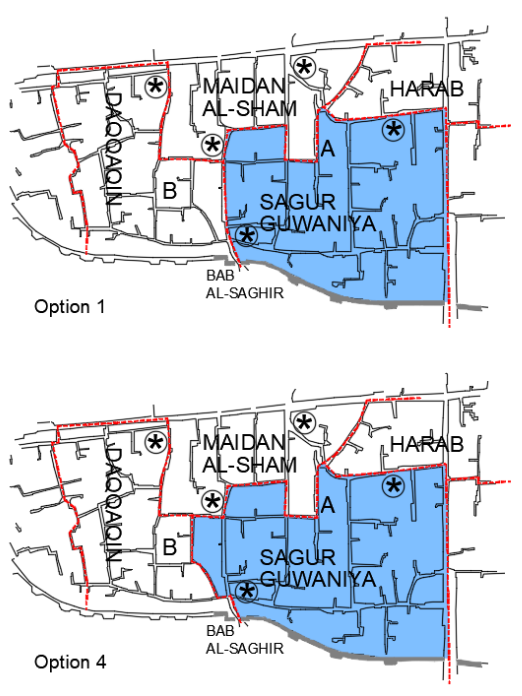
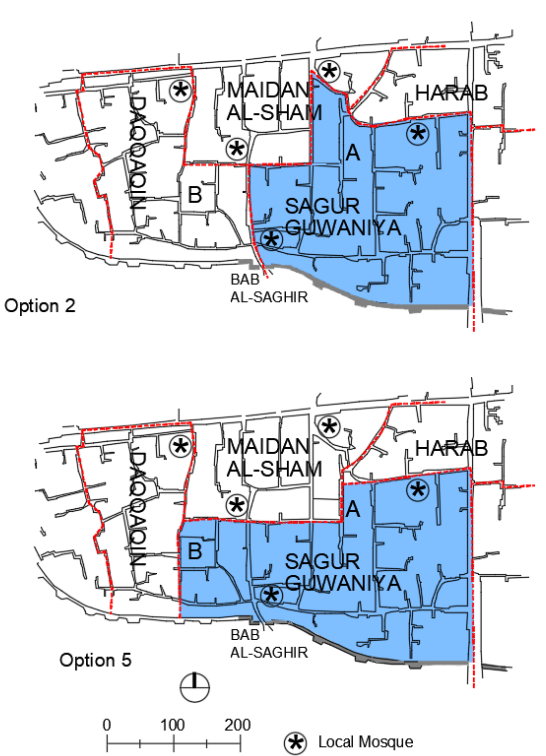

Figure 5. Sagur Guwaniya quarter's mental image boundaries as perceived by inhabitants (source: author) 


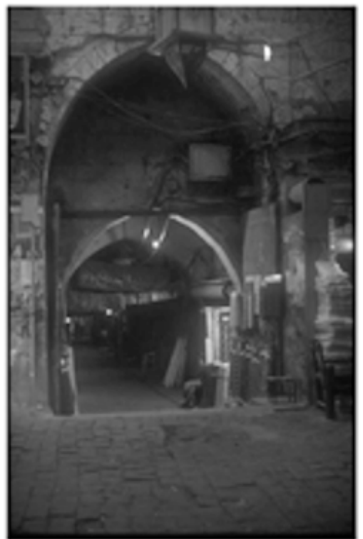

Street gate not lockable

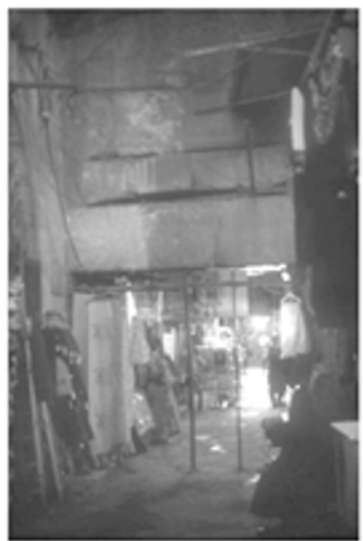

Street gate lockable
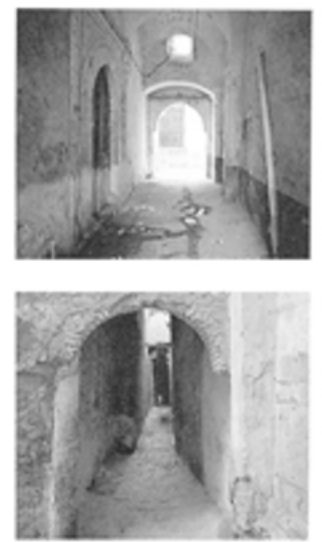

Quarter gate lockable
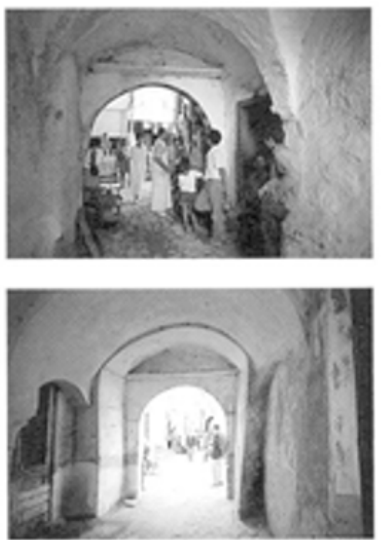

Quarter gate not lockable

Figure 6. Street/Quarter gates in traditional Arab Islamic city (source: author)

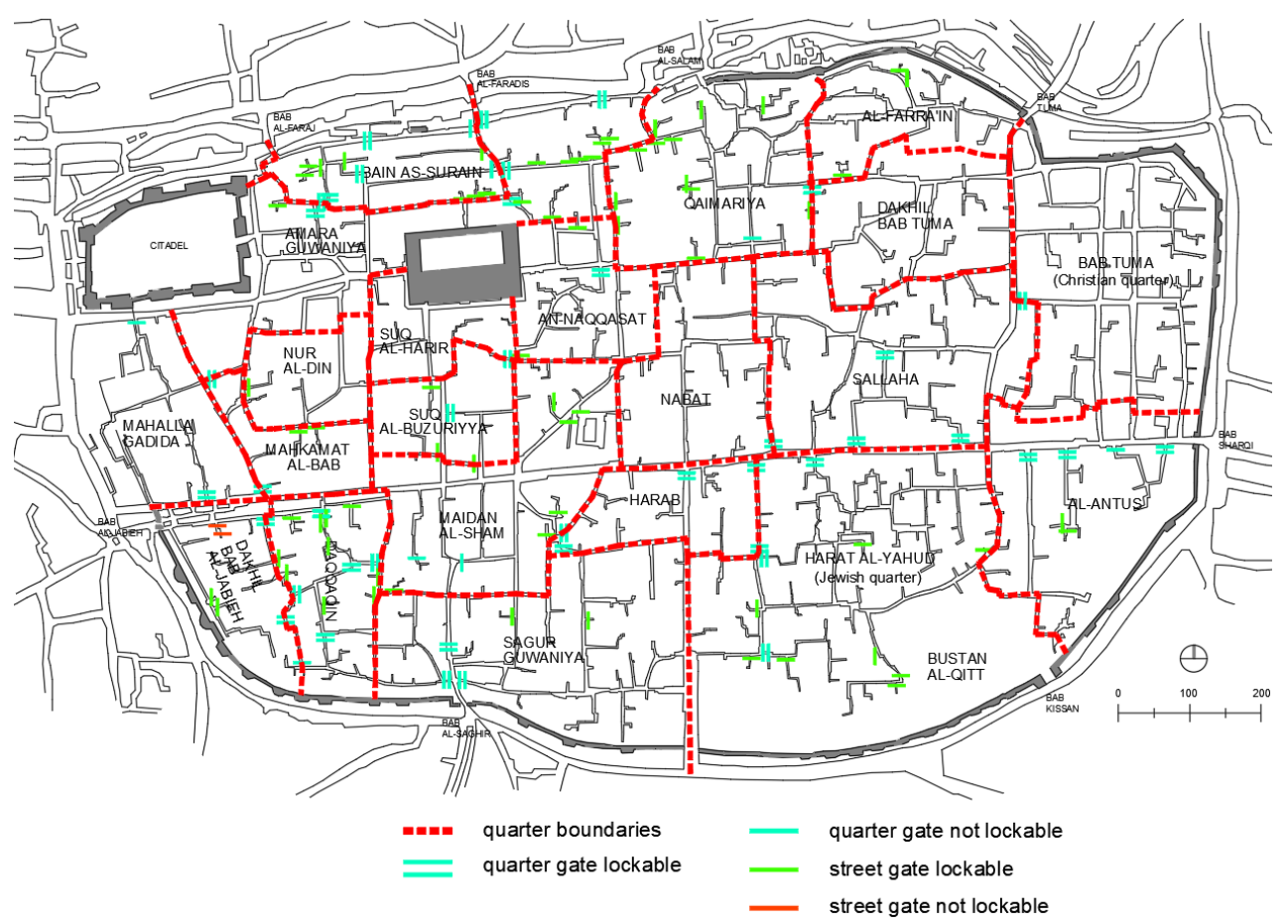

Figure 7. Street/Quarter gates superimposed on quarter boundaries in traditional Arab Islamic city (Damascus) (source: author; Sack, 1989; Chamberlain, 1994; Raymond, 1984, 1997; Pascual, 1983; Sauvaget, 1934)

The not lockable street gates on the other hand are found within the central suq (market) at Bab Al-Jabieh. These gates were located within the suq area to prevent the carriages and animals (used for carrying goods from and to the suq) from entering certain segments of the suq area which is usually very narrow and there is a need to give more space for pedestrian movements within these parts of the suq (Figure 7). The quarter gates are also divided into two types according to Sack; lockable and not lockable (Sack, 1989). The position of the not lockable quarter gates is within the boundaries of the quarter to restrict the movement of strangers into certain limited local streets, as for example in Al-Antus quarter, or to determine a boundary of a Cul-De-Sac, as in Maidan Al-Sham quarter (Figure 7).
As for the lockable quarter gates their position in the city of Damascus is striking as they are not located in a position to determine a quarter boundary, nor are they located on principal street in most cases. Their position can be categorized in three groups; first, they are located to differentiate and restrict the movement of strangers towards one street within the quarter as in Mahalla Gadida, $\mathrm{Al}$-Antus and Bab Tuma quarters. Second they are located within the central suq area to form a closed zone for certain sectors to be locked to provide more security in these areas, as in Daqqaqin and Suq Al-Harir quarters. Third, some are located beside the city gates to provide more protection for these parts of the residential quarters, as in Bab Al-Saghir and Bab Al-Faradis quarters (Figure 7). 
These results show that the boundaries of the quarters do not correspond to the street/quarter gates, which mean that these gates have a different function than defining a quarter boundary; it functions to define the boundary of a private plots and to restrict movement within these private zones and to provide more security within the specialized suq area. By this these observations cast doubt on the pre-conceived idea in most of the literature on Arab Islamic cities as being divided into quarters linked to social groups defined by gates so the residents of the quarters can lock themselves during the unrest in the city (Lapidus, 1969; Hourani, 1970). This is not to deny the existence of neighborhood quarters in the structure of the city, it is to point to the question which was raised earlier regarding the correspondence between the social structure of the city and its physical structure and the quarter as being the determinate factor in structuring the city fabric. From these results it seems that the residents of the quarters in the traditional Arab Islamic city did not live in closed social groups surrounding themselves by walls and gates. On the contrary the quarters were much open towards each other to establish and enhance a social solidarity within the whole community. The boundaries of the quarters were flexible not static expressions of a social system, and even were known to shift from one area of the city to another according to changing circumstances of the population (Azzam, 1993). These results confirm the fact that although these urban quarters did have a certain physical form, they were far from being static expression of a social system. They were dynamic units responding to demographic, social and economic circumstances of the community.

To test these findings, we look at Al-Maidan district in the city of Damascus were we have a well-documented data regarding its process of growth since it was evolved. This district provides a good example of a suburb which evolved under traditional laws within the period of the Islamic rule; it evolved under the Ottomans rule in 1742-1830 AD.

This suburb area was formed by different social groups; the Christians in 1747, the Kurds in 1742-1752, the Turkomans in 1742-1752 and in 1820-1830, the Maghrebies in 1820-1830 and the Egyptians in 18201830 (Raymond, 1997). According to the literature on the traditional Arab Islamic city these social groups (immigrants) should be found to live first, in separate defined quarters, and second, these quarters should be defined physically and bounded by quarter's gates. In reality this was never the situation; different social groups lived next to each other in one quarter; as the Christian and the Kurds in Bab Musalla quarter, the Turkomans, the Kurds and the Egyptians in Suq Al-Midan quarter, the Christians and the Magrebies in Suwayqa quarter, and the Christians in Tayamina quarter (Figure 8). This enhances our conclusions regarding the mobility of these social groups in relation to physical grouping.

In looking at the physical boundaries of the quarters, we allocated all the gates within this district on the quarter's boundary map (Figure 9). The result is striking as all

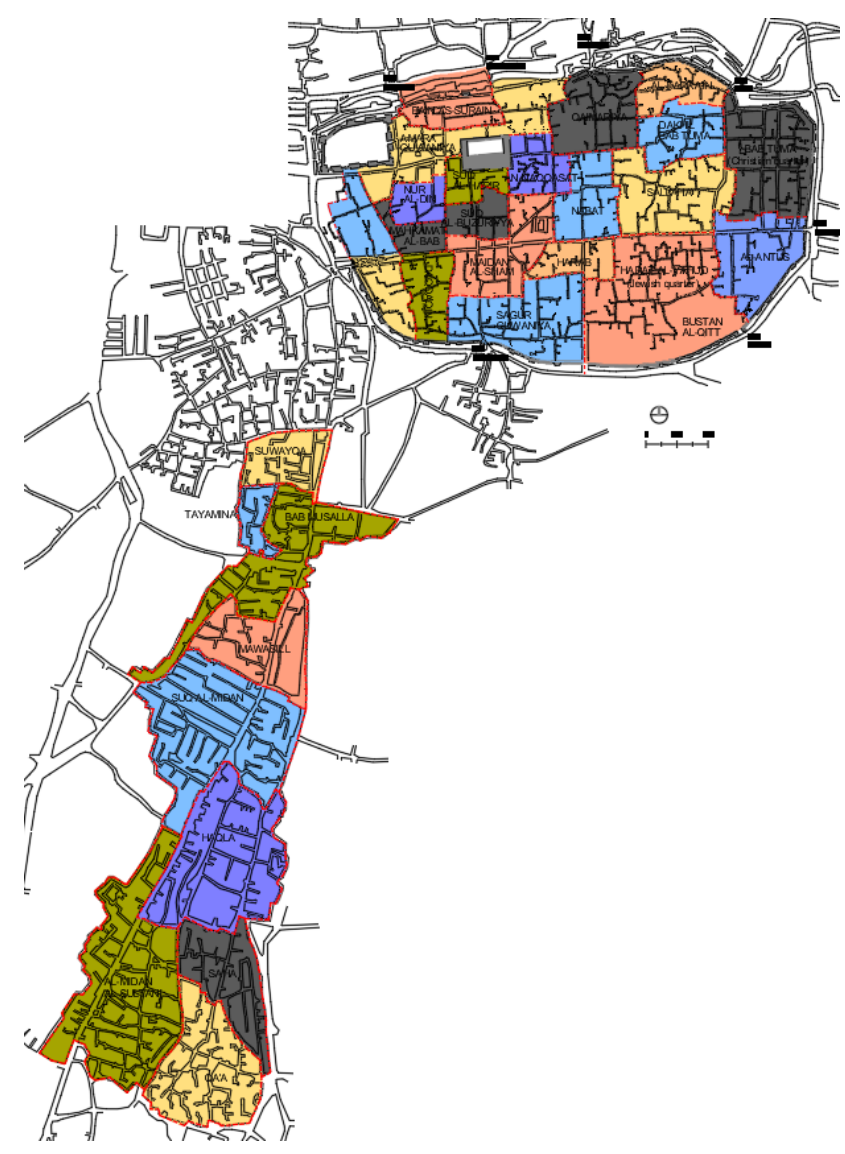

Figure 8. The structure of quarters in Al-Maidan district (Damascus) (source: author; Sack, 1989; Chamberlain, 1994; Raymond, 1984, 1997; Pascual, 1983)

these gates do not correspond to the quarter boundaries at all. They are allocated to define certain streets within the quarters. These gates are: Gate (A) at the edge of Bab Musalla quarter which gives access from a minor street in this quarter to the fields in the west. Gates (B, C, D and E) in Suq Al-Midan quarter define the boundary of a minor street (Cul-De-Sac) within the quarter. It is interesting to note that one social group lived in each of these streets. Gate (B) Zukak Al-Qurashi, Christian, gate (C) Zukak Al-Gawra, Turks, gate (D) Zukak Al-Askari, Kurds, and gate (E) Zukak Al-Mahmas, Christian.

This kind of social grouping leads to the suggestion that one extended family lived in each of these Cul-DeSacs, and this gives them the right to look the entrance of their street by a street gate as it is defining a private property. This again supports the conclusions we reached regarding the street gates in the city of Damascus. The other gates (F) in Suq Al-Maidan quarter, (J) in Al-Midan Al-Sultani quarter and (K) in Qa'a quarter, all of them are located at the edge of the quarter to give access to the fields in the west and the east (Figure 9). Again these arrangements lend support to our findings in the city of $\mathrm{Da}$ mascus, which relate the position of street gates in certain parts of the city to define and restrict the stranger's movement to a local area often owned by one party, and it does not define a quarter's boundary. 


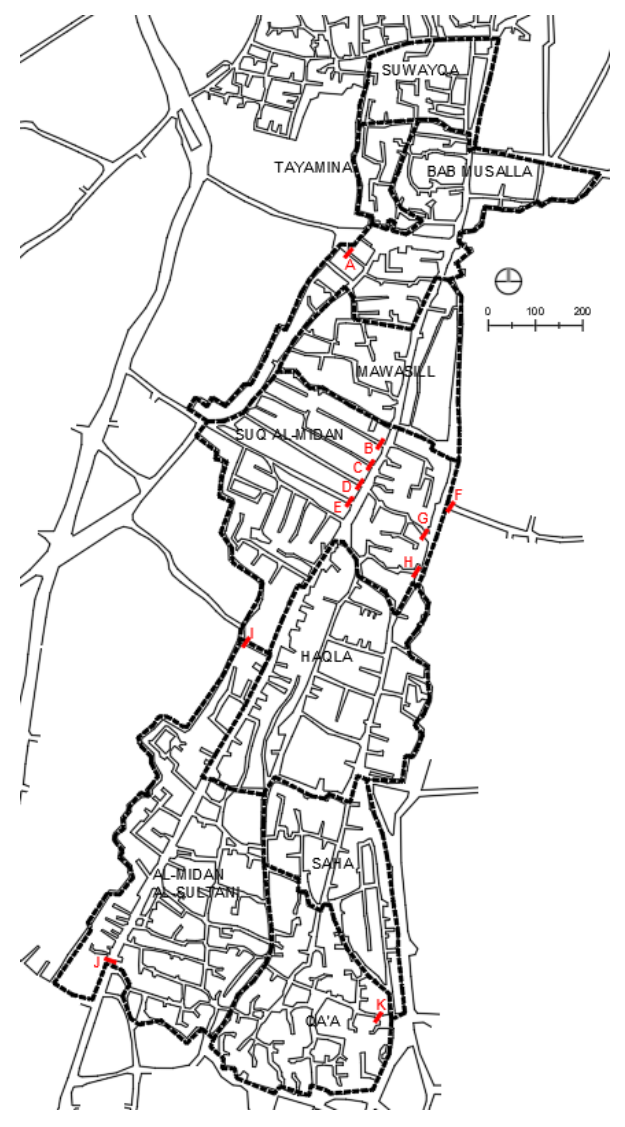

Note: (A) gate to Bab Mussalla; (B) gate to Zukak Al-Qurashi; (C) gate to Zukak Al-Gawra; (D) gate to Zukak Al-Askari; (E) gate to Zukak AlMahmas; (F) gate Al-Ziftiyya; (G) gate Al-Juwaniya; (H) gate Al-Fesiliya; (I) gate Al-Hatab; (J) gate Allah; (K) gate Al-Qa’ah.

Figure 9. Street/Quarter gates superimposed on quarter boundaries in Al-Maidan district (Damascus) (source: author; Sack, 1989; Chamberlain, 1994; Raymond, 1984, 1997; Pascual, 1983)

What this procedure does reveal however, is that for the most part, quarter's boundaries pass through the heart of the urban blocks, tracing property boundaries in route and only occasionally making contact with a segment of the street system. The boundaries of quarters are crosscut by the street system, not in a correspondence to it. This has a number of implications for the concept of the quarters structure. The first is that the boundaries of the quarter are rendered, for the most part, invisible. This is a significant departure from the theoretical model, which predicted clarity through some form of physical expression of the boundary. This is particularly so since what can be marked on a plan frequently cannot be seen in reality. Where boundaries pass through or along party walls, as they do for the most part in the traditional Arab Islamic city, it is not possible to visualize the resulting relational space structure from a point within it. Even where buildings are not erected on both sides of the boundary so that a clear passage is left to one side, this is indistinguishable from the multitude of passages and lanes which are contained entirely within the quarter. Indeed, it is equally plausible to argue a contrary position, that the lack of clar- ity in the boundaries of the quarters disguises differences of allegiance amongst physically adjacent neighbors whose political rights and duties lie in entirely different administrative units.

Of course, it could simply be the case that quarters are defined by groups of streets, so naturally quarter boundaries pass through the blocks, but this does not entirely accord with the way in which quarters were thought to have originated in these cities. If researchers (Lapidus, 1969; Hourani, 1970; Stern, 1970) are correct in their view that quarters originally walled land-holdings, then it might be expected that routes would pass between these rather than through them.

Looking in more detail at the relationship between the street system and quarters, the "weak" hypothesis, that streets are offset at quarter boundaries to make movement between adjacent quarters winding, this does not seem to be the case either. For the most part, through or distributed streets do not acknowledge quarter boundaries by any change of direction. However, it is suggested that the buildup of non-distributed passages (Cul-De-Sac) is governed by quarter boundaries, with a strong tendency for these to terminate at the administrative boundary. Put another way, this would suggest that quarter boundaries are dictated by the extent of individual landholdings, and that landowners were permitted to develop their plots by building back form the main street frontage without any requirement for co-ordination to maintain rights of way through the heart of the block. If this thesis holds, a by-product of the quarter boundaries is to restrict the growth of a secondary route network within the heart of urban blocks.

The view has been interested that quarters were located centrally about a major route to take advantage of through movement. This may well have been the case, but as a motive it is difficult to reconcile to the formulation of the quarters structure for it introduces through movement, particularly by non-residents, into the very heart of the quarter. A comparison of the quarter structure with the open space map suggests that this formulation too is fraught with difficulty, for while in some cases there is no clear candidate for an organizing center. The one statement which can be made without fear of contradiction is that the quarters appear to take up a variety of positions in relation to the street structure.

According to the findings of this sections, the traditional Arab Islamic city appears from its foundation to have been morphologically differentiated in its parts, although the precise way in which this was achieved seems to have varied with historical period and phases of growth. This is clearly at odds with order-based concepts which imply an identity of local elements. Moreover, the sociologically defined concept of a city as a collection of quarters does not seem to be supported by historical investigation. The traditional Arab Islamic city seems to work like a "semi-lattice" in which local identity always goes hand in hand with global relatedness. This combination of local physical differentiation with a high degree of embedding and overlap within a global spatial network seems 
paradoxical. Rossi suggests that the root of this apparent paradox lies in a theoretical insistence on classifying urban space functionally rather than typologically. He argues that "any explanation of urban artefacts in terms of function must be rejected if the issue is to elucidate their structure and formation" (Rossi, 1982). Rossi prefers the study of form as the means to explaining the laws of urban space and structure. This is not to deny the relevance of social process and history but rather to admit that these are often contingent to an understanding of the everyday reality of a city, which is experienced physically as a system of configured street space to use and move about in.

\section{Conclusions and discussions}

This paper has addressed two related questions: are there physically distinctive regions or sub-areas within the traditional Arab Islamic city and, if so, what are they like physically and sociologically.

In answer to the first question, it is argued that the traditional Arab Islamic city indeed made up of sub-areas, but that these are morphological singularities rather than regularities and which "correspond" to historical circumstances by embedding the physical outcome of events within the global urban fabric, rather than corresponding by a process of reflection to social groups.

It is necessary to take a more relativized view of the city than is currently fashionable amongst urban theoreticians. The relation between parts and whole is fundamentally ambiguous, and it is of the nature of the city that a different sub-area picture emerges depending on the point of view of the observer.

It is this intrinsic relativism that needs to be understood in giving an answer to the second question; in specifying the relation between sub-areas and global whole. In one sense, the structure resists disaggregation into physically distinct parts. There does not seem to be any general relation between sub-areas and the routes taken by main streets, well-connected streets, or locally important streets, in the structure. The boundaries between sub-areas, insofar as these can be shown to exist as physically distinct entities, are unclear.

History does seem to differentiate the traditional Arab Islamic city. It is easy to say that these morphological differences are accounted for by historical facts like the location of the Roman temple/church as in the case of Damascus, the building of the mosque and the development of the mosque quarter and the rows of suqs which line it, and the relative stagnation of the quarters and the winding roads in this part of the structure, but a moment's reflection shows that this means nothing unless it is possible to say what each of these measures is expressing, and how they relate to give an overall picture of the city.

In brief, the city is differentiated as a result of historical process rather than of social groupings. However, from the point of view of urban space and structure, historical process means nothing without morphological results.
Historical processes are ephemeral until they impress themselves in the physical form of the city. It is perhaps with good reason that "power" so often seems to engage architecture in the interests of transforming the physical environment in its image, for in so doing it avails itself of a potency which for outlasts the impulse which causes forms to be designed and built. Yet each act of transformation be it the building of a mosque, a fortress, a gateway or a new road- has to be seen as part of a global urban configuration which is itself a social construction, and in which history also play a part. For the configuration of the urban structure gives rise to an interface which both generates and controls human co-presence and encounter, and which is itself subject to processes of fine-tuning and adjustment as social and physical circumstances alter.

The structure of differences within the traditional Arab Islamic city is therefore a concrete instance of the priority which science must give to descriptions rather than causes in seeking to "explain" things. A historical cause may relate to a noted effect, but the mechanism by which the one translates into the other is largely unknown. This is the case with the city, though Rossi might agree that it seems in some sense to be a product of the "social logic" of space itself.

\section{References}

Akbar, J. (1988). Crisis in the built environment: the case of the Muslim city. Concept Media Pte Ltd.

Akbar, J. (1992). Amarat Al-Ardh Fil-Islam. Beirut, Lebanon (in Arabic).

Al-Hathloul, S. A. (1981). Tradition, continuity and change in the physical environment: the Arab-Muslim city [PhD thesis]. Massachusetts Institute of Technology.

Azzam, K. (1993). The Islamic city: a pattern of neighborhood quarters: a case study of the Madinah of Rabat [PhD thesis]. Royal College of Art, London.

Bianca, S. (2000). Urban form in the Arab world: past and present. Thames and Hudson Ltd.

Brown, K. (1986, May 10-14). Middle Eastern cities in comparative perspective [Conference presentation]. Franco-British Symposium, London.

Can, I., \& Heath, T. (2016). In-between spaces and social interaction: a morphological analysis of Izmir using space syntax. Journal of Housing and the Built Environment, 31(1), 31-49. https://doi.org/10.1007/s10901-015-9442-9

Chamberlain, M. (1994). Knowledge and social practice in medieval Damascus (1190-1350). Cambridge University Press. https://doi.org/10.1017/CBO9780511563492

Duri, A. A. (1980). Governmental institutions. In R. B. Serjeant (Ed.), Islamic city. Unesco.

Eickelmann, D. F. (1974). Is there an Islamic city? The making of a quarter in a Moroccan town. International Journal of Middle Eastern Studies, 5(3), 274-294. https://doi.org/10.1017/S0020743800034942

Elisseff, N. (1980). Physical layout. In R. B. Serjeant (Ed.), Islamic city. Unesco.

Ferwati, M. S. (2010). Controllability of traditional neighbourhood and its simplified layout. International Journal of Architectural Research, 4(1), 75-84. 
Gangler, A. (1993). Ein traditionelles Wohnviertel im Nordosten der Altstadt von Aleppo in Nordsyrien. Wasmuth Verlag.

Gaudio, A. (1982). Fez. Joyau de la Civillisation Islamique.

Goddard, C. (1999). The question of the Islamic city [Master thesis]. Institute of Islamic Studies, McGill University, Montreal.

Greenshields, T. H. (1980). Quarters and ethnicity. In G. H. Blake, \& R. L. Lawless (Eds.), The changing Middle Eastern city 120140. Croom Helm.

Habib, F., Moztarzadeh, H., \& Hodjati, V. (2013). The concept of neighborhood and its constituent elements in the context of traditional neighborhoods in Iran. Advances in Environmental Biology, 7(9), 2270-2278.

Hakim, B. S. (1986). Arabic-Islamic cities: building and planning principles. KPI.

Hakim, B. S. (2007). Traditional Islamic and mediterranean urbanism. International Journal of Architectural Research, 1(2), 100-105.

Hertani, M. (1991). Halab: Aswaq Al-Madina: tatawur al-mulkiyah al-'kariyah wa al-fa'aliyat al-iktisadiyah wa al-ijtemaiyah [Aleppo: the Suqs: the development of land ownership, economic and social activities]. Ministry of Culture, Damascus (in Arabic).

Hourani, A. H. (1970). The Islamic city in the light of recent research. In A. H. Hourani, \& S. M. Stern (Eds.), The Islamic city. Oxford.

Khoury, P. S. (1984). Syrian urban politics in transition: the quarters of Damascus during the French mandate. International Journal of Middle East Studies, 16(4), 507-540.

Lapidus, I. M. (1967). Muslim cities: the later middle ages. Harvard University Press.

Lapidus, I. M. (1969). Muslim cities and Islamic societies. In Middle Eastern cities. University of California Press. https://doi.org/10.1525/9780520323803-006

Lapidus, I. M. (1970). Muslim urban society in Mamluk Syria. In A. H. Hourani, \& S. M. Stern (Eds.), The Islamic city. Oxford.

Le Tourneau, R. (1961). Fez in the age of the marinides. University of Oklahoma Press.

Lynch, K. (1981). A theory of good city form. MIT Press.

Luz, N. (2014). The neighborhood: social and spatial expressions. In The Mamluk city in the Middle East: history, culture, and the urban landscape (Cambridge Studies in Islamic civilization, pp. 84-104). Cambridge University Press.

https://doi.org/10.1017/CBO9781107270114.007

Marcus, A. (1989). The Middle East on the eve of modernity: Aleppo in the $18^{\text {th }}$ century. Cambridge University Press.

Pascual, J. P. (1983). Damas: à la fin du XVI siècle. Institut Français de Damas.

Perry, C. A. (1939). The neighborhood unit formula. In Housing for the machine age. Russell Sage Foundation.

Raymond, A. (1984). The great Arab cities in the $16^{\text {th }}$ and $18^{\text {th }}$ centuries an introduction. New York University Press.

Raymond, A. (1989). La Medina de Tunis: espace historique. Presses du CNRS.

Raymond, A. (1997). Le faubourg du Midan à Damas à lépoque ottomane: espace urbain, société et habitat (1742-1830). Institut Français de Damas.

Raymond, S. (1985). Grandes villes arabes à l'époque ottomance. Sindbad.

Rapoport, A. (1982). Scared places, sacred occasions and sacred environments. Architectural Digest, 52(9/10), 76.

Remali, A. M., \& Porta, S. (2017). Street networks and streetblocks in the city centre of Tripoli. Urban Morphology, 21(2), 161-179.

Rossi, A. (1982). The architecture of the city (D. Ghirardo, \& J. Ockman, Trans.). MIT Press.

Sack, D. (1989). Damaskus: Entwicklung und struktur einer orientalisch-islamischen stadt. Verlag Philipp von Zabern.

Sauvaget, J. (1934). Esquisse d'une hitoire de la ville de Damas. Revue des études islamiques, VIII(4).

Serjeant, R. B. (1980). The Islamic city: selected papers from the colloquium held at the Middle East center. Unesco.

Stern, S. M. (1970). The constitution of the Islamic city. In A. H. Hourani, \& S. M. Stern (Eds.), The Islamic city: a colloquium (pp. 25-50). Bruno Cassirer, University of Pennsylvania Press.

Von Grunebaum, G. E. (1961). The structure of the Muslim town. In Islam: essays in the nature of growth of a cultural tradition. Routledge \& Kegan Paul, Barnes \& Noble.

Woodford, J. S. (1990). The city of Tunis: evolution of an urban system. Middle East and North Africa Studies Press. 